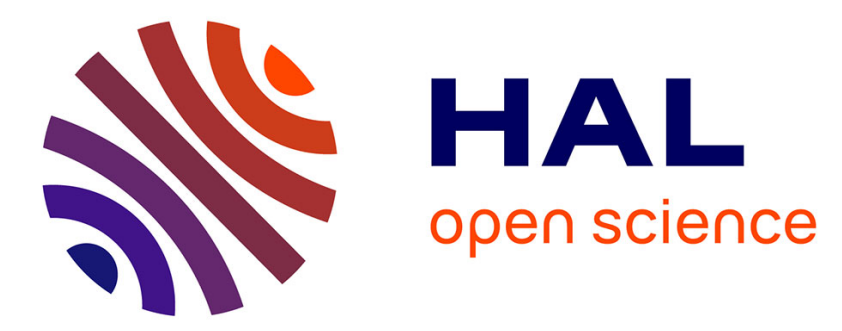

\title{
Merging several separate data acquisition systems at GANIL
}

\author{
G. Wittwer, L. Legeard, G. Lebertre, B. Raine, L. Olivier
}

\section{To cite this version:}

G. Wittwer, L. Legeard, G. Lebertre, B. Raine, L. Olivier. Merging several separate data acquisition systems at GANIL. 14th Conference on Real Time (RT2005), Jun 2005, Stockholm, Sweden. 2005, pp.427-428, 2006. in2p3-00105175

\section{HAL Id: in2p3-00105175 https://hal.in2p3.fr/in2p3-00105175}

Submitted on 11 Oct 2006

HAL is a multi-disciplinary open access archive for the deposit and dissemination of scientific research documents, whether they are published or not. The documents may come from teaching and research institutions in France or abroad, or from public or private research centers.
L'archive ouverte pluridisciplinaire HAL, est destinée au dépôt et à la diffusion de documents scientifiques de niveau recherche, publiés ou non, émanant des établissements d'enseignement et de recherche français ou étrangers, des laboratoires publics ou privés. 


\title{
Merging several separate data acquisition systems at GANIL
}

\author{
G. Wittwer, L. Legeard, G. Lebertre, B. Raine, L.Olivier \\ GANIL \\ BP 55027 \\ F-14076 Caen Cedex 05 FRANCE
}

\begin{abstract}
The Grand Accélérateur National d'Ions Lourds (GANIL) as a National User's Facility must answer to the problems of synchronization for the coupling of resident and external acquisition systems. For this a solution made up of a $\mathrm{C}$ size VXI electronics called CENTRUM[1] and of software named MERGER was adopted. The technique used for synchronization is based on the distribution of a 32-bit event number or a 48-bit timestamp. The tagged events sent by the various acquisition systems on the network are assembled by MERGER in a single event and sent for the analysis and storage.
\end{abstract}

\section{INTRODUCTION.}

The aim of this project was to answer to the philosophy of new experiments that take place at GANIL where for example a silicon detector (TIARA) has been coupled to a gamma ray spectrometer (EXOGAM) and a particle spectrometer (VAMOS) [2]. Each detector has its own setup system and data acquisition software (DAS and GANIL Acquisition for VAMOS, MIDAS [3] for EXOGAM and TIARA)

\section{GANIL HARWARE CONTEXT}

At the beginning of the nineties, GANIL get the knowledge of a new standard for instrumentation called Vme eXtension for Instrumentation (VXI) [4] due to the built of the $4 \pi$ INDRA [5] detector. The use of D-size mainframes which could accommodate VXI standard D-size modules permitted a high level of integration. Few years later, another challenge was the renovation of the electronic used in non-specific data acquisition systems mainly composed of old CAMAC triggers and converters. In taking account our know-how of VXI and the robustness plus the EMC qualities of that standard, the choice of C-size VXI has been made to design and produce new modules (A C-size VXI electronics for DAQ at GANIL) [6]. Thereafter, all the experimental rooms have been equipped progressively with C-size VXI crates. More recently, the EXOGAM and VAMOS spectrometers use D-size and C-size VXI respectively. That's for what, at the time of the specifications writing, the C-size VXI has been chosen as the board standard for CENTRUM. Today, GANIL is able to propose a full set of VXI functions with the coupling capability between acquisitions systems.

\section{ELECTRONIC SOLUTION}

CENTRUM is the acronym for Clock Event Number Transmitter Receiver Universal Module, so there is two main ideas in this electronic designed at GANIL at the beginning of the $2 \mathrm{~K}$ years.
The first one was: what type of information must be sent to the individual data acquisition system to correlate events from different detectors? The second point was: what type of hardware, in which standard, to transmit or receive information?

Physicists and engineers agreed to the fact that two pieces of common distributed information could suit most of coupled configurations and that a new module must be the same board for both ends, only differentiated by the software setup.

- The first information is a 32-bit event number that can be used in systems that are in common dead time. This is an interlocked mechanism currently used in nuclear physics. In this scenario the current value of an event counter kept in a CENTRUM, declared by software as master, controlled by the master trigger of that data acquisition, is sent to slave data acquisition equipped with a CENTRUM declared as slave. All that on request depending if that subsystem has triggered or not. In the positive case, these separate DAQs add this received event number to their data buffer and broadcast it on the network to a processor. Then, a program running in this machine called "MERGER" correlates individual events and builds the full final event. The drawback of this method is that the total dead time per event is decided by the slowest acquisition.

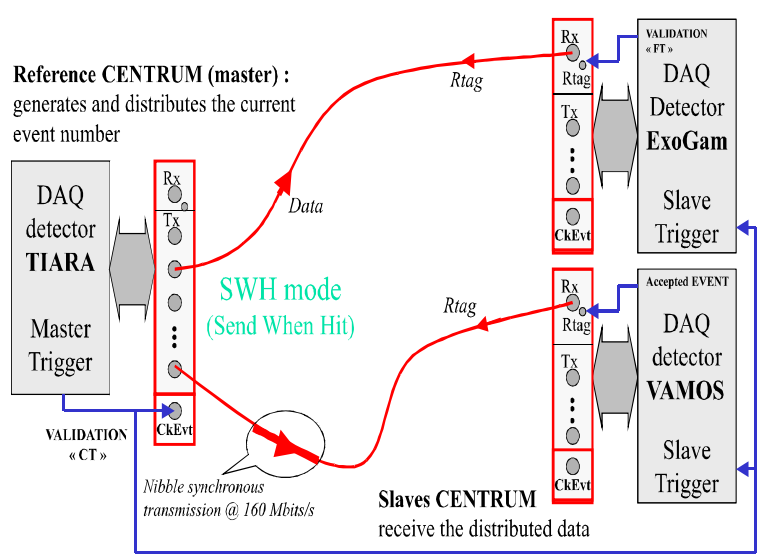

Fig.1. EVENT NUMBER mode block diagram

- The second information uses an absolute time reference. The concept here is that each system ask for the time. A 48-bit counter clocked by a $100 \mathrm{MHz}$ oscillator (10ns resolution), enabled in only one referenced CENTRUM is started at the beginning of the experiment. This one will give the information to its own system (i.e. where it resides) but also to each DAQ that is coupled and contains a distributed CENTRUM. When a trigger validates an event in one data acquisition system, a 
tagging pulse is sent by the CENTRUM inserted in that subsystem. In return, this one receives from the referenced CENTRUM the timestamp information. This technique allows free running data acquisition systems; no interlock is required. The big part of work for synchronization is made later around a fixed gate value by the same software tool MERGER.

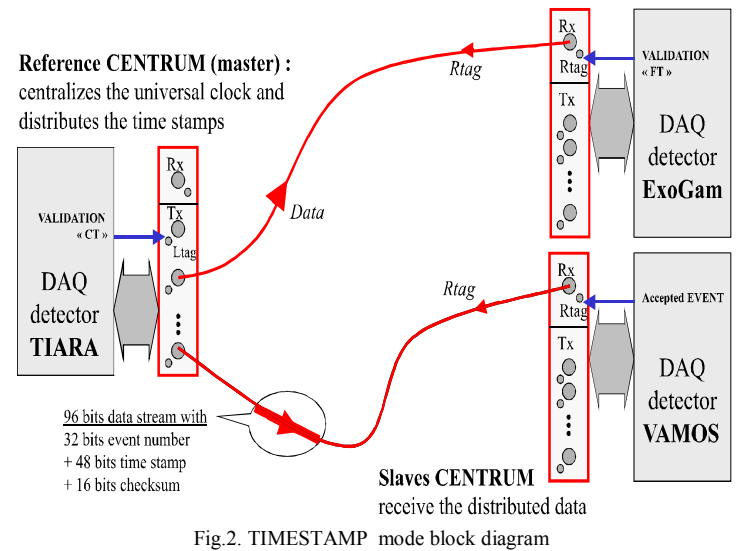

The CENTRUM module has been developed in C size VXI to fit in all the crates available at GANIL. This module is controlled internally by a TCXO oscillator to insure less than $1 \mathrm{ppm}$ of derating, especially for the timestamp operator. The CENTRUM, equipped with a SHARC DSP, is able to send information to seven remote data acquisition systems at 160 $\mathrm{Mbit} / \mathrm{s}$ for distance up to $25 \mathrm{~m}$ via a dedicated SHARC LINK PORT.

\section{SOFTWARE SOLUTION}

MERGER software [7] is an event builder. It assembles events which come from multiple physically separated front- ends and sends the result of this concatenation to analysis workstations and a tape server. MERGER is written in $\mathrm{C}++$, runs on PowerPC VME CPU under Lynx OS or Pentium Linux station and is multithreaded.

The data treatment is separated in 3 levels (Fig3):

-The first one collects the buffers from the network. The source of buffers is identified with an identifier number. These buffers are stored in a stack. The format of buffers is EBYEDAT [8] and contains the source identifier in his header.

-In a second level, a sorter process dispatches the events in as much event stack as number of source identifiers. A master process scans these stacks.

In case of event number mode, the builder process tries to match the same event number in other event stacks. The concatenation of these events gives a new event. If no match, the events are just sent as they are.

In case of timestamp mode, the builder process does practically the same thing, but the concatenation is validated if the time difference between the event fragments is less than a fixed interval.
-In a third level, the new events are encapsulated in new buffers where source identifier is erased. These buffers are sent to the tape server and analysis workstations through the network.

When several front-ends and the tape server are used, it can be useful to have a unique control command. This has been done with a configurable graphical interface made in Java for the user commands like "stop" or "start" which controls all individual detector data acquisition system.

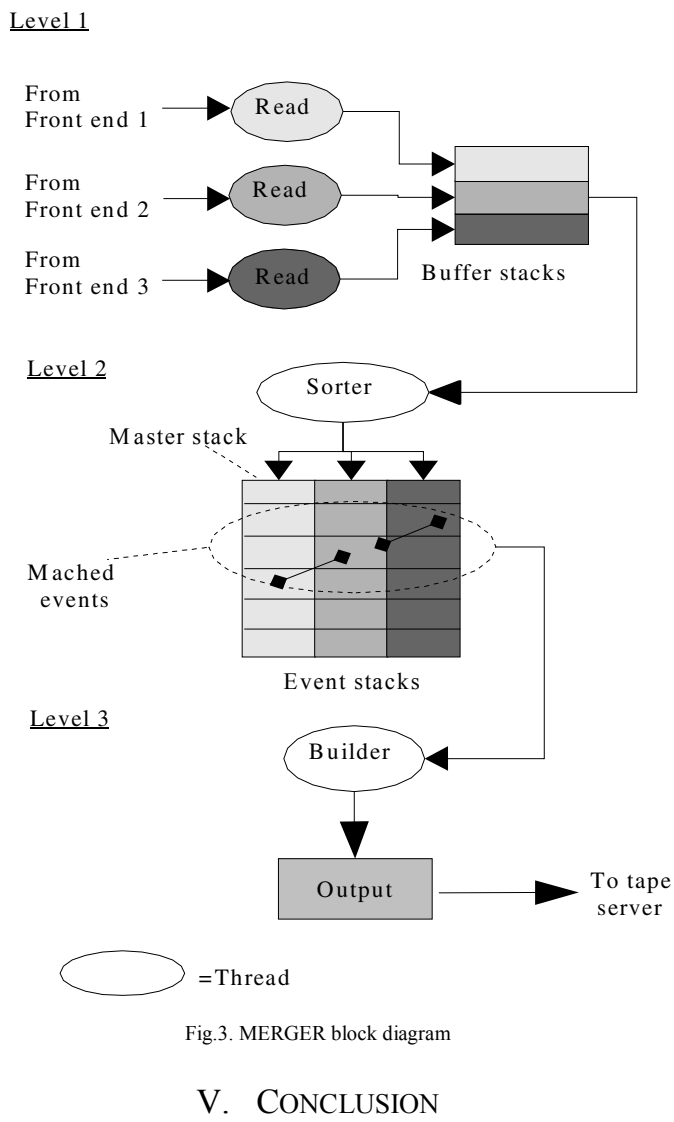

This system has already been used for more than ten experiments with two or three detectors at Ganil with success. Thus, new couplings between other detectors with CENTRUM and MERGER are in discussion.

\section{REFERENCES}

[1] G. Wittwer , "Clock Event Number Transmitter Receiver Universal Module", User's Manual, GANIL July 2004

[2] www-aix.gsi.de/ wolle/EB_at_GSI/FRS-WORKING/ MINUTES/MEETING 16 $\bar{A} P \bar{R} /$ r.lemon.pdf

[3] http://nnsa.dl.ac.uk/MIDAS/

[4] VMEbus Extension for Instrumentation, TEK- CDS, VXIbus System Specification Revision 1.3 - July 14,1989

[5] INDRA, a $4 \Pi$ charged product detection array at GANIL, GANIL P 9426

[6] L. Olivier, "a C-size electronics for DAQ at GANIL", Nouvelles du GANIL n63, 1998

[7] http://www-dapnia.cea.fr/Sphn/Deformes/Exotag/11052004/ Bruno.pdf

[8] http://nnsa.dl.ac.uk/documents/edoc417/edoc417.html 